\title{
Azotlu ve kükürtlü gübrelemenin çılak köklü Toros sediri (Cedrus libani A. Rich.) fidanlarının gelişimi üzerine etkileri
}

\author{
Nevzat Gürlevik, ${ }^{\mathrm{a}, *}$, Mutlu Mercan ${ }^{\mathrm{b}}$
}

\begin{abstract}
Özet: Fidan kalitesini etkileyen en önemli faktörlerden birisi toprak verimliliğidir. Fidanlıklarda toprağın aşırı asidik veya alkali olması, havalanmasının yeterli olmaması veya fidanların aşırı sık olması gibi nedenler fidanlarda beslenme ve gelişim bozukluklarına neden olabilmektedir. Bu çalışmada, fidan gelişiminin zayıf olduğu fidanlık yastığında, azotlu ve kükürtlü gübrelemenin 1+0 yaşlı çıplak köklü Toros sediri (Cedrus libani A. Rich.) fidanları üzerine etkileri araştırılmıştır. Bu amaçla, tesadüf parselleri deneme desenine uygun olacak şekilde, 1 kontrol ve 3 gübreleme işlemi (N10: $10 \mathrm{~g} \mathrm{~N} \mathrm{~m}^{-2}, \mathrm{~S} 11: 11 \mathrm{~g} \mathrm{~S} \mathrm{~m}^{-2}$ ve S75: $75 \mathrm{~g} \mathrm{~S} \mathrm{~m}^{-2}$ ) üç tekrarlı olarak denemeye alınmıştır. Vejetasyon mevsimi sonunda toprak reaksiyonundaki değişim ve fidanların morfolojik özellikleri belirlenmiştir. Ayrıca, gübrelemenin fidanların $\mathrm{N}$ ve $\mathrm{S}$ beslenmesine etkileri de belirlenmiştir. Sonuçta, N10 işleminin fidanların morfolojik özellikleri üzerine belirgin bir etkisinin olduğu, ancak S11 ve S75 işlemlerinin önemli farlılıklar yaratmadığı görülmüştür. TSE kalite sınıflandırmasına göre, N10 gübrelemesiyle $\mathrm{m}^{2}$ de 315 kaliteli fidan elde edilmişken kontrol parselinde yalnızca 34 kaliteli fidan elde edilmiștir. Sonuç olarak, Eğirdir Orman Fidanlığında yürütülen çıplak köklü Toros Sediri fidanı yetiştirme çalışmalarında azotlu gübreleme yapılması gerekliliği ortaya konmuştur. Anahtar kelimeler: Toros sediri, Gübreleme, Azot, Kükürt, Fidan morfolojisi, Görüntü analizi, Fidan kalitesi
\end{abstract}

\section{Effects of nitrogen and sulfur fertilization on development of bare-root Taurus cedar (Cedrus libani A. Rich.) seedlings}

\begin{abstract}
Soil productivity is one of the most important factors affecting seedling quality. Unfavorable conditions such as excessively acidic or alkaline soil reaction, poor aeration or over-dense seedlings may results in nutritional and developmental abnormalities in forest nurseries. In this study, effects of nitrogen and sulfur fertilization on $1+0$ year-old bare root Taurus cedar (Cedrus libani A. Rich.) seedlings were investigated in a nursery bed, where some nutritional and growth problems are commonly observed. One control and three fertilizer treatments (N10: $10 \mathrm{~g} \mathrm{~N} \mathrm{~m}^{-2}$, S11: $11 \mathrm{~g} \mathrm{~S} \mathrm{~m}^{-2}$ and S75: $75 \mathrm{~g} \mathrm{~S} \mathrm{~m}^{-2}$ ) were applied in accordance with randomized block design with three replications. Changes in soil reaction and morphological properties of seedlings were determined at the end of the growing season. In addition, effects of fertilization on $\mathrm{N}$ and $\mathrm{S}$ nutrition of the seedlings were determined. As a result, it was determined that N10 treatment had a pronounced effect on morphological properties of the seedling, but S11 and S75 treatments did not have any significant effect. According to TSE seedling quality classes, N10 fertilization resulted in 315 quality seedlings per $\mathrm{m}^{2}$, while number of quality seedling were 34 seedlings per $\mathrm{m}^{2}$ in control treatment. As a conclusion, it was shown that N10 fertilization is necessary when growing bare-root Taurus cedar in Eğirdir Forest Nursery.
\end{abstract}

Keywords: Taurus cedar, Fertilization, Nitrogen, Sulfur, Seedling morphology, Image analysis, Seedling quality

\section{Giriş}

Ülkemizde yöresel olarak "katran ağacı" olarak da bilinen Toros sediri (Cedrus libani A. Rich.) ormanları tarihsel, kültürel, biyolojik, estetik ve ekonomik açllardan büyük önem taşımaktadır. Toros sediri çok değerli odun özellikleri nedeniyle tarihsel süreçte doğal ormanları en fazla tahrip edilen türler arasında yer almaktadır. Dünyada doğal yayılışını Anadolu, Lübnan ve Suriye'de yapan bu tür 5000 yıllık tahribat sonucu günümüzde en büyük doğal ormanlarını ülkemizde kurmaktadır (Sevim, 1955; Mayer ve Sevim, 1959; Boydak ve Çalıkoğlu, 2008).

Toros sediri, doğal yayılış alanları dışındaki ağaçlandırmalarda uyum yeteneğinin yüksek olması ve odununun değerli olması gibi nedenlerle hem ülkemizde hem de yurt dışında ağaçlandırma çalışmalarına konu olmuştur (OGM, 2005; Boydak ve Çalıkoğlu, 2008). Son yıllarda başarıyla uygulanan karpelli tohum ekimi ve fidan dikimi yöntemleriyle, önceden hasar örmüş doğal sedir ormanları Akdeniz illerimizde tekrar eski sağlıklı yapılarına kavuşturulmaya çalışılmaktadır (Boydak, 2014; OGM, 2015). Günümüzde Orman Genel Müdürlüğü fidanlıklarında üretilen orman ağacı türleri içerisinde, Toros sediri yıllık yaklaşık 66 milyon fidanla karaçamın (Pinus nigra) hemen ardından ikinci sırada yer almaktadır (OGM, 2015).

Toros sediri doğal olarak, nispeten kurak ve kalkerli yamaçlarda çoğu kez kayalar arasında yetişebilmektedir. Özellikle gevşek yapılı, geçirgen ve havalanması iyi

\footnotetext{
\ a Süleyman Demirel Üniversitesi, Orman Fakültesi, 32260, Isparta

b Muğla Oman Bölge Müdürlüğü, Bodrum Orman İşletme Şefliği, Muğla

@ * Corresponding author (İletişim yazarı): nevzatgurlevik@ sdu.edu.tr

$\checkmark$ Received (Geliş tarihi): 08.12.2016, Accepted (Kabul tarihi): 27.12.2016
}

Citation (Atıf): Gürlevik, N., Mercan, M., 2017. Azotlu ve kükürtlü gübrelemenin çılak köklü Toros sediri (Cedrus libani A. Rich.) fidanlarının gelișimi üzerine etkileri. Turkish Journal of Forestry, 18(1): 21-29 DOI: $10.18182 /$ sduofd. 273816 
toprakları tercih eder. Buralar genellikle orta veya kaba tekstürlü, nötr veya hafif alkalin reaksiyonu topraklardır. Serin ve derin topraklarda iyi bir gelişme ve büyüme gösterir (Atalay, 1987; Kantarcı, 1990; OGM, 2008, Boydak 2014). Fidanlık şartlarında da benzer şekilde durgun su problemi olmayan, kaba tekstürlü yastıklarda iyi gelişim göstermektedir. Genelde orman fidanlıklarında sağlıklı üretim için, kil+toz içeriğinin \% 50'den az olması, organik madde içeriğinin \% 2'den fazla olması, kireç içeriğinin \% 10'dan düşük olması gibi bazı kriterler sayılabilir (Gülçur 1959, 1962a,b; Örtel, 1994). Ayrıca topraktan hem makro hem de mikro besinlerin alınabilirliği açısından toprak pH'sının 6-7 civarında olması önerilmektedir, zira alkali topraklarda metalik elementlerin çözünürlüğü büyük oranda azalmaktadır (van den Driessche, 1984). Ancak ülkemiz fidanlıklarının pek çoğu sedir fidanları için ideal şartları taşımamaktadır.

Eğirdir fidanlığındaki topraklar da, yüksek kil ve kireç içeriği, yüksek pH ve düşük organik madde içeriği gibi nedenlerden dolayı havalanma ve beslenme sorunları göstermektedir (Özçelik ve Özkan, 1997). Bu mevcut durum, fidanların gereğinden sık yetiştirilmesi (Albayrak Çatal, 2002; Yıldız 2005), aşırı sulama, otlanma vb. kültürel sorunlarla daha da ciddi seviyelere ulaşabilmektedir. Bütün bu olumsuzluklar fidanlıkta istenen kalitede fidanların elde edilememesine, üretimin önemli bir kısmının ıskarta fidan olarak israf edilmesine, dolaysıyla fidan maliyetlerinde artışlara neden olabilmektedir (Alkan, 2002).

Fidanlıklarda ortaya çıkabilecek gelişim bozuklularını gidermede kullanılabilecek yöntemlerden birisi de gübrelemedir. Gübreleme kısaca toprakta yeteri kadar bulunmayan ya da toprakta bulunmasına karşın çeşitli sebeplerden dolayı (yüksek $\mathrm{pH}$, havalanma, aşırı veya az su sorunu vb.) bitkiler tarafından yeteri kadar alınamayan besin elementlerinin toprağa veya doğrudan bitkiye verilmesi işlemidir. Verilen gübreler çeşitli niteliklerde olabilir, doğrudan veya dolaylı olarak fidanlık toprağını ve fidanları etkileyebilirler (Karaöz, 1992; Havlin vd, 1999; Gürlevik ve Gültekin, 2009, Katkat ve Kacar, 2011; Brohi vd, 2012).

$\mathrm{Bu}$ çalışmada, Eğirdir Orman Fidanlığındaki sedir fidanlarında gözlemlenen kloroz ve zayıf gelişim gibi olumsuzlukları giderebilmek amacıyla, $\mathrm{N}$ ve $\mathrm{S}$ gübrelemesi yapılmış ve bu gübrelerin çıplak köklü fidanların gelişimi üzerinde etkileri araştırılmış̧ır. Azotun fidanlık toprağında yetersiz olduğu ve bu besinin bitki dokularında (klorofilin, aminoasitlerin ve enzimlerin yapısında bulunması gibi) hayati öneme sahip olması münasebetiyle fidan gelişimini arttıracağı varsayılmıştır. Kükürdün ise doğrudan fidan gelişimini etkilemekten çok, toprakta fazlaca bulunun kireci nötralize ederek, halihazırda yüksek olan toprak reaksiyonunu düşüreceği varsayılmıştır. Böylece, alkali topraklarda alınabilirliği düşük olan $\mathrm{Fe}, \mathrm{Mn}, \mathrm{Zn}, \mathrm{Cu}$ gibi metal elementlerin alabilirliğini artırarak kloroz sorununun önüne geçilebileceği varsayılmıştır.

\section{Materyal ve yöntem}

\subsection{Tohum materyali}

Çalışma kullanılan tohumlar Isparta Orman İşletme Müdürlüğü, Senirkent Orman İşletme Şefliğii, Kapıdağ Serisi, Sedir tohum meşceresinden toplanmıştır. Tohum meşceresi 1984 yılında tesis edilmiş olup, rakımı $1650 \mathrm{~m}$, bakis1 ise kuzeydir (OATIAM, 2009).

\section{2. Ĕ̈irdir Orman Fidanlı̆̆l}

Fidanlık çalışmaları Isparta Orman Bölge Müdürlüğü bünyesinde bulunan Eğirdir Orman Fidanlığında gerçekleştirilmiştir. Eğirdir Orman Fidanlığı; 37 53' kuzey enlemi $30^{\circ} 52^{\prime}$ doğu boylamı üzerinde, ortalama $926 \mathrm{~m}$ rakımda tesis edilmiştir. Fidanlık 1962 yılında 20 hektarlık bir alan üzerine kurulmuş olup, fidanlığın üretim kapasitesi y1llık 7,2 milyon adettir (Anonim, 1999). Bu araştırma Eğirdir Orman Fidanlığı merkez sahasının 10 numaralı parselinde yürütülmüştür. Fidanlığın genel iklim ve toprak özellikleri Çizelge 1'de verilmiştir.

Fidanlık toprağı derelerin getirdiği alüvyal toprakların birikmesi ile oluşmuştur. Toprak türü genelde kumlu-killibalçık iken, yer yer killi balçık ve kildir. Sulama, EğirdirKovada gölleri arasında bulunan sulama kanalından yapılmaktadır. Topoğrafik yönden koridor biçiminde uzanan boğaz tabanında yer aldığından, kuzey-güney yönünden esen şiddetli rüzgarlara maruz kalmaktadır. Fidanlık Akdeniz iklimi ile karasal ikliminin geçiş bölgesinde yer almakla birlikte, karasal iklimin etkisi daha fazla hissedilmektedir (Anonim, 1999).

\subsection{Fidanlık çalışmaları}

Tohum ekim işlemi Şubat ayı başında $100 \mathrm{~g} \mathrm{~m}^{-2}$ tohum olacak şekilde elle çizgi ekimi yöntemiyle yapılmıştır. İlkbaharla birlikte, fidan sıklığının homojen ve fidanların genel sağlık durumunun iyi olduğu gözlenen bir yastık deneme parseli olarak seçilmiştir. Denemenin kurulduğu yastıkta fidan sıklığ metrekarede ortalama 548 adet ile normalde hedeflenen 250-300 fidandan çok daha yüksektir.

Kontrol ve üç farklı gübreleme işleminin uygulanacağı parseller Mayıs ayının ikinci haftasında tesadüf parselleri deneme desenine uygun olacak şekilde 3 tekrarlı olarak oluşturulmuştur (Çizelge 2). Her parsel 1,2 m eninde ve 1,0 $\mathrm{m}$ boyunda olacak şekilde çıtalarla ayrılmış ve bu parseller arasında 25 cm'lik tampon bölge birakılmıştır. Örneklenecek fidanlar tampon bölge dışındaki ortada kalan kısımdan alınmıştır. Ayrıca kenar etkisinden kaçınmak amacıyla 1. ve 7. kenar sıralardan fidan örneği alınmamıştır.

Çizelge 1. Eğirdir Orman Fidanlığının konum ve iklim özellikleri (Anonim, 1999)

\begin{tabular}{ll}
\hline Özellik & Değer \\
\hline Konum & $37^{\circ} 53^{\prime} \mathrm{K}, 30^{\circ} 52^{\prime} \mathrm{D}$ \\
Rakım & $926 \mathrm{~m}$ \\
Yıllık ortalama sıcaklık & $12,3^{\circ} \mathrm{C}$ \\
Yıllık maksimum sıcaklık & $34,7^{\circ} \mathrm{C}$ Temmuz) \\
Y1llık min. sıcaklık & $-9,1^{\circ} \mathrm{C}$ (Şubat) \\
Y1llık ortalama nispi nem & $\% 65,9$ \\
Yıllık ortalama mak. nispi nem & $\% 76,7$ (Aralık) \\
Y1llık ortalama min. nispi nem & $\% 46$ (Temmuz) \\
Yıllık ortalama yağıŞ & $839,7 \mathrm{~mm}$ \\
En yağışlı ay & Ocak \\
En kurak ay & Ağustos \\
Ortalama rüzgar hızı & $3,0 \mathrm{~m} / \mathrm{sn}$ \\
Kar kaplı gün & 8 gün \\
Yııllık donlu gün & 94,0 gün \\
\hline
\end{tabular}


Çizelge 2. Denemede kullanılan gübreler ve uygulama dozlar1

\begin{tabular}{|c|c|c|}
\hline İşlem & $\operatorname{Doz}\left(\mathrm{g} \mathrm{m}^{-2}\right)$ & Gübre türü ve içeriği \\
\hline Kontrol (K) & 0 & Gübre uygulanmamıştır \\
\hline Azot (N10) & 10 & $\begin{array}{l}\text { Amonyum sülfat } \\
\left(\mathrm{NH}_{4} \mathrm{SO}_{4} ; \% 21 \mathrm{~N}, \% 24 \mathrm{~S}\right)\end{array}$ \\
\hline Kükürt (S11)* & 11 & Toz kükürt ( \% $99 \mathrm{~S})$ \\
\hline Kükürt (S75)** & 75 & Toz kükürt ( \% $99 \mathrm{~S})$ \\
\hline
\end{tabular}

Gübreler fidan sıraları arasına çizgi halde serpilmiş ve toprağın 0-5 cm'lik üst kısmına çapa ile karıştırılmıştır. Bu işlemin hemen ardından aynı gün içerisinde sulama yapılarak gübrenin toprağa nüfuzu sağlanmıştır. Vejetasyon mevsimi boyunca Eğirdir Fidanlığının rutin fidanlık uygulamalarına paralel olacak şekilde sulama, ot alımı vb. bakım işlemleri uygulanmıştır. Sulama haftada bir ya da iki kez yağmurlama sistemi ile yapılmıştır. Ot alma işlemi de sulama işleminden sonra toprak tavda iken elle otların kökten koparılması şeklinde vejetasyon dönemi içerisinde iki kez tekrar edilmiştir.

Fidanlık toprağının genel özelliklerini belirlemek amaciyla 0-10 cm derinlikteki üst topraktan, her parselden en az üç farklı noktadan 0,5 litre kadar bozulmuş toprak örnekleri alınmış ve laboratuvara getirilmiştir. Hava kurusu hale getirilen topraklar öğütülüp $2 \mathrm{~mm}$ 'lik elekten geçirildikten sonra fiziksel ve kimyasal analize hazır hale getirilmiştir. Örnekler daha sonra Eğirdir Bahçe Kültürleri Araştırma Enstitüsü Tarımsal Analiz Laboratuvarında analiz edilmiştir. Tekstür Bouyoucos hidrometre yöntemi (Demiralay, 1993), tuzluluk 1/2,5'lik karışımda iletkenlik ölçer ile (U.S. Salinity Lab. Staff, 1954), pH 1/2,5'lik karışımda cam elektrotlu pH metre ile (Peech, 1965), kireç Scheibler kalsimetresi ile (Hizalan ve Ünal, 1966), organik madde Smith-Weldon yöntemi ile (Hocaoğlu, 1966), değişebilir $\mathrm{K}, \mathrm{Ca}, \mathrm{Mg}, \mathrm{Na}$ amonyum asetat yöntemiyle (Kacar, 1995), alınabilir P sodyum bikarbonat yöntemiyle (Kacar, 1995), $\mathrm{Fe}, \mathrm{Mn}, \mathrm{Zn}, \mathrm{Cu}$ ise DTPA $+\mathrm{CaCl}_{2}+$ TEA yöntemiyle (Lindsay ve Norvell, 1978) analiz edilmiştir. Değişebilir iyon ölçümleri ICP (Inductively Coupled Plasma Atomic Emission Spectophometer) cihazı ile yapılmıştır. Ayrıca, toprak reaksiyonundaki değişimleri belirlemek için mayıs (gübrelemeden hemen önce), temmuz ve ocak aylarında (söküm esnasında) yine üst topraktan alınan örneklerde $\mathrm{pH}$ ölçümleri yapılmıştır.
Mevsim sonunda 16 Ocak 2009 tarihinde her parselden 25 adet olmak üzere 4 parselden 3 tekrarlı toplam 300 adet fidan sökülüp nemli telislere sarılarak laboratuvara götürülmüştür. Fidanlar üzerindeki morfolojik ölçümler birkaç gün içerisinde tamamlanmış, fidanlar ölçüm zamanına kadar nemli serin ortamda bekletilmiştir.

\subsection{Laboratuvar çalışmaları}

\subsubsection{Morfolojik ölçümler}

Laboratuvarda fidanlar telislerden çıkarılarak önce musluk suyu ile iyice yıkanmış ve topraktan arındırılmıştır. Sonra ilk iş olarak kök boğazından itibaren $20 \mathrm{~cm}$ uzaklıktan kök tımarı gerçekleştirilmiştir. Akabinde fidanların boyu, kök boğazı çapı, yan kök sayısı $(>1 \mathrm{~cm})$, kök ucu sayısı ve en uzun yan kök uzunluğu ile kök ve gövde firın kurusu ağırlıkları $\left(70{ }^{\circ} \mathrm{C}\right.$ 'de) belirlenmiştir. Fidan çap ve boy değerlerinden hareketle üretilen fidanların TSE standartlarına (TS2265, 1988) göre dağılımı belirlenmiştir. Ayrıca gürbüzlük katsayısı, gövde/kök oranı ve Dickson kalite indeksi (Dickson vd., 1960) aşağıdaki gibi hesaplanmıştır:

- Gürbüzlük katsayısı: Fidan boyu (mm) / kök boğazı çapı (mm)

- Gövde/Kök Oranı: Gövde kuru ağırlığı (g) / kök kuru ağırlığı (g)

- Dickson Kalite İndeksi: Toplam fidan kuru ağırlığ $(\mathrm{g}) /\{$ [ Boy $(\mathrm{cm}) /$ Çap $(\mathrm{cm})]+[$ Gövde kuru ağırlığı (g) / Kök kuru ağırlığı $(\mathrm{g})]$ \}

\subsubsection{Dijital fotoğraflar vasıtasıyla kök yüzey alanlarının tespiti}

Her parselden 10'ar kök örneği (toplamda 120 adet) alınarak standart A4 kâğıdı üzerinde dijital fotoğraf makinesi ile 90 derecelik bir kadraj sağlanarak sabit bir odak mesafesinden fotoğraflanmıştır (Şekil 1). Her örnekten 3 fotoğraf alınmış ve kök yüzey alanını belirlemek için en iyi görüntü kalitesi sunan bir fotoğraf kullanılmıştır. Görüntüler bilgisayar ortamında 300 dpi çözünürlükte ve yine standart A4 $(297 \mathrm{~mm}$ x $210 \mathrm{~mm})$ ebadında olacak şekilde piksel ayrıntısına inilerek cetvel aracı vasıtasıyla özenle işaretlenmiş ve kırpılmıştır. Bir sonraki adımda ise fotoğraflar RGB Color'dan Grayscale'e çevrilmiştir. Ardından kökün piksel sayısı A4 kağıdının piksel sayısına oranlanarak kökün $\mathrm{cm}^{2}$ cinsinden alanı bulunmuştur.

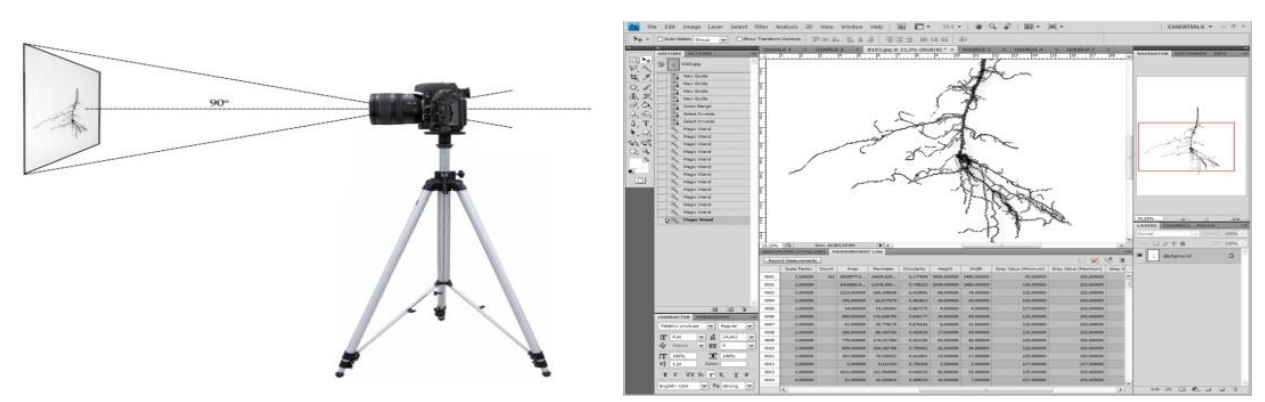

Şekil 1. Fidanların dijital kök görüntülerinin alınması ve bilgisayarda piksel sayılarının belirlenmesi 


\subsubsection{Fidanlarin beslenme durumu}

Denemede kullanılan her bir işlem için ayrı ayrı olmak üzere; fırın kurusu haldeki örneklerde ibreler gövde sapından ayrılarak, fidanlar ibre, gövde ve kök kısımlarına ayrılmıştır. Bu örnekler blender yardımı ile öğütülerek toz haline getirilip hava almayan kilitli poşetlere konulmuş ve Eğirdir Bahçe Kültürleri Araştırma Enstitüsü Tarımsal Analiz Laboratuvarında besin içerikleri bakımından analiz edilmiştir. Analizlerde azot ıslak yakmaya dayalı Kjeldahl yöntemi ile, diğer elementler ise kuru yakmaya dayalı olarak ICP ile tayin edilmiştir (Ryan vd., 2001).

\subsection{Veri analizi}

Elde edilen tüm veriler SPSS yazılımı ile varyans analizine tabi tutulmuştur. İstatistiksel farklılık belirlenmesi halinde ise Duncan testi ile homojen gruplar belirlenmiştir.

\section{BULGULAR}

\subsection{Toprak özellikleri}

Araştırmanın yürütüldüğü sahanın genel toprak özelliklerini yansıtan karma toprak örneğinin analiz sonuçları Çizelge 3'de verilmiştir. Buna göre çalışma yürütülen fidanlık yastığındaki toprağının \% 32'lik bir kil içeriğiyle nispeten ağır bünyeli ve 8,18 ile orta dereceli alkali olduğu görülmektedir. Bunun yanında, kireç, kalsiyum ve demir dışında diğer elementler bakımından orta veya düşük seviyededir.

Deneme alanından mayıs (işlem öncesi), temmuz ve ocak (söküm aşaması) aylarında her parselden alınan toprak örneklerine ait $\mathrm{pH}$ ölçüm değerleri Çizelge 4'de verilmiştir. Mayıs ayına ait $\mathrm{pH}$ ölçümleri neticesinde işlemler arasında belirgin bir fark görülmemiştir. Ancak temmuz ayı ölçümlerinde $\mathrm{K}$ işlemine göre; N10 işleminde 0,16'lık, S11'de 0,34'lük, S75'te 0,42'lik bir düşüş gerçekleşmiştir. Ocak ayındaki ölçümlere bakıldığı zaman ise pH'lar arasında önemli bir fark görülmezken yalnızca $\mathrm{K}$ işlemine göre S75 işlemiyle pH'da 0,18'lik bir düşüş görülmüştür.

\subsection{Fidan morfolojik özellikleri}

Birinci vejetasyon mevsimi sonunda çıplak köklü sedir fidanlarının kontrol işlemindeki boyları ortalama $3,9 \mathrm{~cm}$ ve kök boğazı çapları ise 2,3 mm olarak bulunmuştur (Çizelge 5). Kükürtlü işlemlerin fidan özellikleri üzerine bariz bir etkisi görülmemiştir. Azotlu gübreleme ise boy gelişimini yaklaşık \%72 artırarak 6.8 cm'ye çıkarmış, ancak çap gelişimini etkilememiştir. Azotlu gübrelemenin boyda artışa neden olup çap1 etkilememesi boy/çap oranını da etkilemiştir (Şekil 2). Bu oran kontrol için 17 olurken, N10'da 28, S11'de 24, S75'de ise 19 olarak bulunmuştur. Fidanlardaki gelişim farklılıkları kuru ağırlıklara da benzer şekilde yansımıştır. Azotlu gübreleme sonucunda gövde kütlesinde \% 72'lik, kök kütlesinde ise \% 15'lik bir artış görülmüştür. Gövdenin bir kısmını oluşturan ibre kütlesinde de ciddi bir artış görülmüştür. Bir yaşındaki bu genç fidanlarda ibre kütlesi toplam toprak üste gövde kütlesinin yaklaşık \% 66-71'ini teşkil etmektedir. Kök yüzey alanında da benzer şekilde yaklaşık \% 23'lük bir artış görülmüştür. Bu durumda gövde/kök oranı da kontrolde 1.14'ten N10'da 1.69'a çıkmıştır. Azotlu işlem fidan kalite indeksini ise etkilememiştir. Bunun dışındaki kök sayısı ve kök uzunluğu parametreleri ne azottan ne de kükürtten etkilenmiştir. Kükürt etkisi yalnızca S11 işleminde çapta ve kalite indeksinde küçük bir düşüş olarak öne çıkmış ve bu durum muhtemelen bu işlem grubundaki parsellerde fidan sıklığının daha fazla olmasından kaynaklanmıştır.

Çizelge 3. Toprak analiz sonuçları

\begin{tabular}{lcc}
\hline Ölçülen özellik & Ölçüm sonucu & Açıklama \\
\hline Kum $(\%)$ & 54 & - \\
Toz $(\%)$ & 13 & - \\
Kil $(\%)$ & 32 & - \\
Toprak Türü & Kumlu killi balçık & - \\
Tuzluluk $\left(\mathrm{mS} \mathrm{m}^{-2}\right)$ & 125 & Tuzsuz \\
pH $\left(1: 2,5 \mathrm{H}_{2} \mathrm{O}\right)$ & 8,18 & Hafif alkali \\
Kireç $(\%)$ & 13 & Yüksek \\
Organik Madde $(\%)$ & 3,6 & Orta \\
Fosfor (ppm) & 18 & Orta \\
Potasyum (ppm) & 153 & Orta \\
Kalsiyum (ppm) & 4026 & Yüksek \\
Magnezyum (ppm) & 257 & Düşük \\
Sodyum (ppm) & 17,43 & Düşük \\
Demir (ppm) & 9,05 & Çok Yüksek \\
Bakır (ppm) & 1,50 & Orta \\
Mangan (ppm) & 11,46 & Orta \\
Çinko (ppm) & 0,45 & Düşük \\
\hline
\end{tabular}

Çizelge 4. Deneme alanından toprak örneklerinin üç farklı aydaki pH ölçüm sonuçları

\begin{tabular}{lcccccc}
\hline \multirow{2}{*}{ İşlem } & \multicolumn{2}{c}{ Mayıs } & \multicolumn{2}{c}{ Temmuz } & \multicolumn{2}{c}{ Ocak } \\
\cline { 2 - 7 } & $\mathrm{Su}$ & $\mathrm{KCl}$ & $\mathrm{Su}$ & $\mathrm{KCl}$ & $\mathrm{Su}$ & $\mathrm{KCl}$ \\
\hline $\mathrm{K}$ & 7,88 & 7,24 & 8,09 & 7,33 & 8,01 & 7,27 \\
N10 & 7,93 & 7,22 & 7,93 & 7,31 & 7,97 & 7,26 \\
S11 & 7,97 & 7,24 & 7,75 & 7,30 & 7,99 & 7,26 \\
S75 & 7,90 & 7,25 & 7,67 & 7,26 & 7,83 & 7,21 \\
\hline
\end{tabular}

Çizelge 5. Azotlu ve kükürtlü gübrelemenin sedir fidanlarının morfolojik özellikleri üzerine etkileri ( \pm 1 standart sapma)

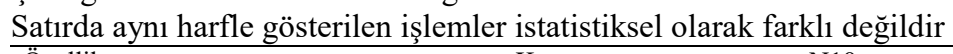

\begin{tabular}{|c|c|c|c|c|}
\hline Özellik & $\mathrm{K}$ & $\mathrm{N} 10$ & S11 & S75 \\
\hline Fidan boyu $(\mathrm{cm})$ & $3,9 \pm 1,4 b$ & $6,8 \pm 2,4 \mathrm{a}$ & $4,4 \pm 1,8 \mathrm{~b}$ & $4,1 \pm 1,7 \mathrm{~b}$ \\
\hline Kök boğazı çapı (mm) & $2,3 \pm 0,4 a b$ & $2,4 \pm 0,4 \mathrm{a}$ & $2,0 \pm 0,3 \mathrm{c}$ & $2,1 \pm 0,5 \mathrm{bc}$ \\
\hline Yan kök sayısı (adet) & $10,5 \pm 4,1$ & $10,2 \pm 3,1$ & $10,3 \pm 3,7$ & $9,3 \pm 3,3$ \\
\hline Kök ucu sayısı (adet) & $86,3 \pm 40,5$ & $85,6 \pm 43,7$ & $78,1 \pm 32,8$ & $73,3 \pm 37,6$ \\
\hline En uzun yan kök uzunluğu (cm) & $9,3 \pm 2,4$ & $9,4 \pm 2,8$ & $9,9 \pm 2,7$ & $9,3 \pm 3,0$ \\
\hline Kök yüzey alanı $\left(\mathrm{cm}^{2}\right)$ & $7,8 \pm 2,4 b$ & $9,6 \pm 2,8 \mathrm{a}$ & $7,5 \pm 1,9 b$ & $7,4 \pm 2,3 b$ \\
\hline Gövde kuru ağırlığı $(\mathrm{g})^{*}$ & $0,37 \pm 0,14 b$ & $0,64 \pm 0,31 \mathrm{a}$ & $0,36 \pm 0,16 b$ & $0,39 \pm 0,18 b$ \\
\hline İbre kuru ağırlığı (g) & $0,25 \pm 0,05 \mathrm{~b}$ & $0,44 \pm 0,11 \mathrm{a}$ & $0,25 \pm 0,05 \mathrm{~b}$ & $0,26 \pm 0,08 b$ \\
\hline Kök kuru ağırlığı (g) & $0,33 \pm 0,11 \mathrm{~b}$ & $0,39 \pm 0,15 \mathrm{a}$ & $0,30 \pm 0,11 b$ & $0,33 \pm 0,12 b$ \\
\hline Gövde/kök oranı & $1,14 \pm 0,31 \mathrm{~b}$ & $1,69 \pm 0,49 \mathrm{a}$ & $1,17 \pm 0,27 \mathrm{~b}$ & $1,20 \pm 0,27 b$ \\
\hline Fidan kalite indeksi & $0,25 \pm 0,08 \mathrm{a}$ & $0,23 \pm 0,08 \mathrm{a}$ & $0,20 \pm 0,06 \mathrm{~b}$ & $0,23 \pm 0,08 \mathrm{a}$ \\
\hline
\end{tabular}

* Gövde örnekleri, gövde odunu ve üzerindeki ibreler dahil fidanın tüm toprak üstü kısmını ifade etmektedir. 


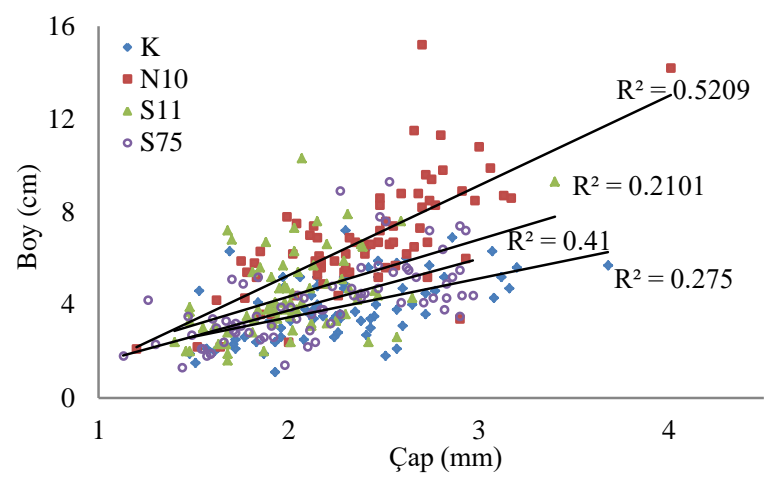

Şekil 2. Fidan boyu ile kök boğazı çapı arasındaki ilişki

\subsection{Fidanların TSE kalite standartları açısından değerlendirilmesi}

TS2265 nolu ve Şubat 1988 tarihli iğne yapraklı ağaç fidanları standardına göre bir yaşındaki sedir fidanının en az $2 \mathrm{~mm}$ çapta, en az $6 \mathrm{~cm}$ boyda olması ve gövde/kök oranının en fazla 4 olması istenmektedir. Buna göre, çalışmada elde edilen fidanların büyük çoğunluğu hem boy hem de çap bakımından standart dışı (ıskarta) kalmaktadır (Çizelge 6). Kontrol işleminde üretilen fidanların \% 92'si boy bakımından ve \% 28'i ise çap bakımından ıskartaya ayrılmıştır. Veriler hem boy hem de çap için birlikte değerlendirildiğinde, kontrol işlemindeki fidanların \% 93'ünün 1skarta olduğu görülmüştür (Şekil 3). Buna karşın, N10 işleminde fidanların \% 43'ü S11'de \% 87, S75'te ise fidanların \% 89'si iskartaya ayrılmıştır. Neticede N10 ișlemiyle $\mathrm{m}^{2}$ de 315 kaliteli fidan elde edilirken, $\mathrm{K}$ işleminde yalnızca 34, S11'de 84 adet ve S75'te ise 54 adet kaliteli fidan elde edilmiştir.

\subsection{Fidan besin konsantrasyonu ve içeriği}

Fidanların ibre, gövde odunu ve köklerinde bulunan besin konsantrasyonları Çizelge 7'de verilmiştir. Buna göre, N'lu ve S'lü gübrelemenin ibre, gövde ve kökte besin konsantrasyonuna etkileri oldukça sınırlı kalmıştır. Sadece S11 ve S75 işlemleri ibrelerdeki kükürt konsatrasyonunu yaklaşık \% 60 artırmışlardır. Azot gübrelemesinde ise ibre azot konsantrayonu artmak bir yana, $\mathrm{K}$ işleminde \% 1,58 iken N10 işleminde bu oran \% 1,38'e gerilemiştir. Ayrıca, fidan kısımları kendi aralarında karşılaştırıldığında ibrelerin gövde ve kök odununa göre daha yüksek makrobesin konsantrasyonlara sahip olduğu, buna karşın mikrobesinlerde ibrelerin bu üstünlügünü kaybettiği görülmektedir. $\mathrm{Fe}$ ve $\mathrm{Cu}$ gibi metallerde kök dokularındaki konsatrayonun çok daha yüksek olduğu görülmektedir.

Fidanların bir birim alandan kaldırdıkları besin maddeleri incelendiğinde, azot gübrelemesinin bitkilerin topraktan aldığı besin maddesi miktarını artırdığı görülmüştür (Çizelge 8). Örneğin, kontrol işleminde $1 \mathrm{~m}^{2}$ lik fidanlık yastığından bir yılda $2,8 \mathrm{~g} \mathrm{~N}$; $0,24 \mathrm{~g} \mathrm{P}$; ve $0,64 \mathrm{~g} \mathrm{~K}$ alınmışken, $\mathrm{N}$ gübrelemesinde bu değerler artarak 4,4 $\mathrm{g} \mathrm{N}$; $0,34 \mathrm{~g} \mathrm{P}$ ve $1,34 \mathrm{~g} \mathrm{~K}$ olarak gerçekleşmiştir. Kontrole kıyasla bu artışın oranı N, P ve K için sırasıyla 1,6; 1,4 ve 2,1 kat olmuştur.

Çizelge 6. Ortalama fidan boyu (FB) ve kök boğazı çapına (KBÇ) göre fidanların kalite sınıflarına yüzdelik dağılımı

\begin{tabular}{|c|c|c|c|c|c|c|c|}
\hline \multirow[b]{2}{*}{ İşlem } & \multicolumn{4}{|c|}{ FB Kalite Sınıfları } & \multicolumn{3}{|c|}{ KBÇ Kalite Sınıfları } \\
\hline & $\begin{array}{l}\text { Ort. FB } \\
(\mathrm{cm})\end{array}$ & $\begin{array}{c}\text { I. sinif } \\
\text { FB } \geq 8 \\
\%\end{array}$ & $\begin{array}{c}\text { II. sinıf } \\
8>\mathrm{FB} \geq 6 \\
\%\end{array}$ & $\begin{array}{c}\text { Iskarta } \\
\mathrm{FB}<6 \\
\%\end{array}$ & $\begin{array}{l}\text { Ort. KBÇ } \\
(\mathrm{mm})\end{array}$ & $\begin{array}{c}\text { Kaliteli } \\
\mathrm{KBÇ} \geq 2 \\
\%\end{array}$ & $\begin{array}{c}\text { Iskarta } \\
\mathrm{KBÇ}<2 \\
\%\end{array}$ \\
\hline $\mathrm{K}$ & 3,9 & 0,0 & 8,0 & 92,0 & 2,3 & 72,0 & 28,0 \\
\hline N10 & 6,8 & 26,7 & 33,3 & 40,0 & 2,4 & 82,7 & 17,3 \\
\hline S11 & 4,4 & 2,7 & 14,7 & 82,7 & 2,0 & 50,7 & 49,3 \\
\hline S75 & 4,1 & 2,7 & 8,0 & 89,3 & 2,1 & 58,7 & 41,3 \\
\hline
\end{tabular}
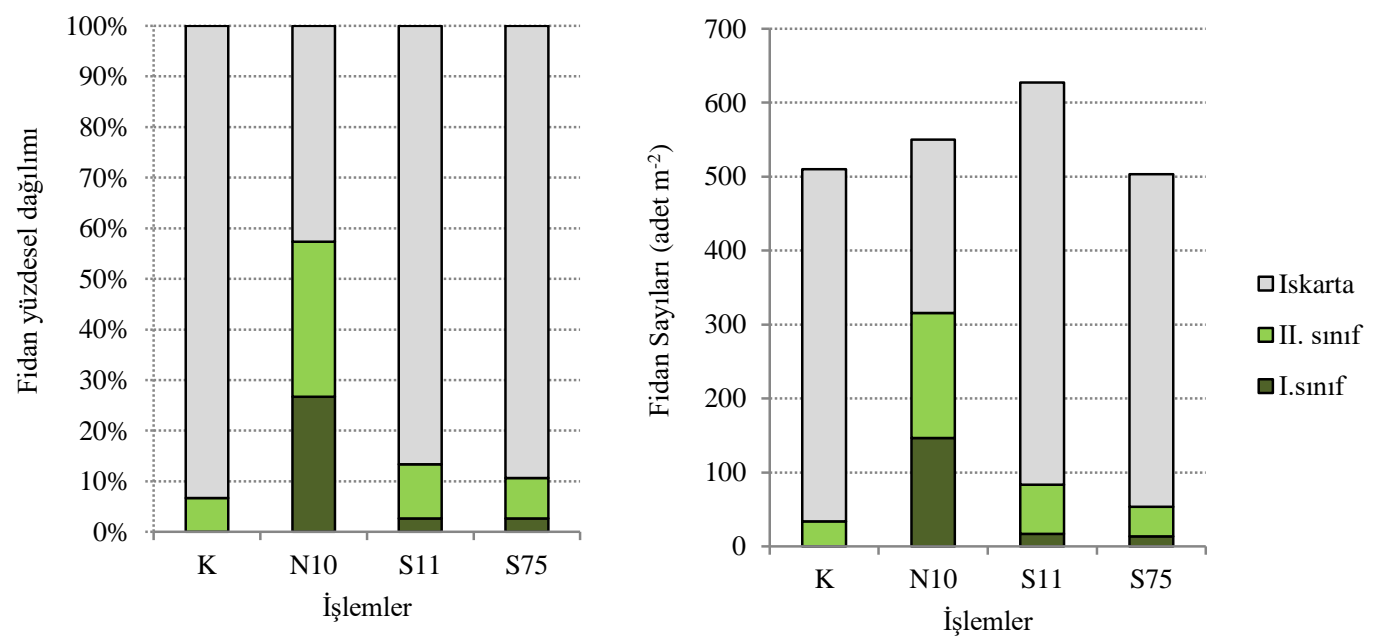

Şekil 3. Üretilen fidanların TSE standartlarına göre I. sınıf, II. sınıf ve ıskarta fidan sınıfına girenlerinin yüzdesel ve adetsel dağılımı (hem boy hem de çap göz önünde bulundurularak) 
Çizelge 7. Bir yaşlı çıplak köklü sedir fidanlarının ibre, gövde odunu ve köklerindeki besin konsantrasyonları (aynı harfle gösterilen işlemler istatistiksel olarak farklı değildir)

\begin{tabular}{|c|c|c|c|c|c|c|c|c|c|c|c|c|}
\hline İ̇slem & $\begin{array}{c}\mathrm{N} \\
(\%)\end{array}$ & $\begin{array}{c}\mathrm{P} \\
(\%)\end{array}$ & $\begin{array}{c}\mathrm{K} \\
(\%)\end{array}$ & $\begin{array}{l}\mathrm{Ca} \\
(\%)\end{array}$ & $\begin{array}{l}\mathrm{Mg} \\
(\%)\end{array}$ & $\begin{array}{c}\mathrm{S} \\
(\%)\end{array}$ & $\begin{array}{c}\mathrm{Fe} \\
(\mathrm{ppm})\end{array}$ & $\begin{array}{c}\mathrm{Cu} \\
(\mathrm{ppm})\end{array}$ & $\begin{array}{c}\mathrm{Mn} \\
(\mathrm{ppm})\end{array}$ & $\begin{array}{c}\mathrm{Zn} \\
(\mathrm{ppm})\end{array}$ & $\begin{array}{c}\mathrm{B} \\
(\mathrm{ppm})\end{array}$ & $\begin{array}{c}\text { Mo } \\
(\mathrm{ppm})\end{array}$ \\
\hline \multicolumn{13}{|l|}{ Íbre } \\
\hline K & 1,58 & 0,13 & $0,34 \mathrm{a}$ & 1,38 & 0,19 & $0,10 \mathrm{a}$ & 338 & 10 & 62 & 51 & 49 & 6,0 \\
\hline $\mathrm{N}$ & 1,38 & 0,10 & $0,40 \mathrm{~b}$ & 1,24 & 0,18 & $0,11 \mathrm{a}$ & 434 & 7 & 59 & 36 & 44 & 2,5 \\
\hline S11 & 1,50 & 0,11 & $0,45 b$ & 1,19 & 0,18 & $0,16 b$ & 280 & 11 & 68 & 53 & 60 & 6,2 \\
\hline $\mathrm{S} 75$ & 1,56 & 0,12 & $0,37 \mathrm{a}$ & 1,41 & 0,19 & $0,16 \mathrm{~b}$ & 238 & 7 & 58 & 41 & 43 & 2,5 \\
\hline \multicolumn{13}{|l|}{ Gövde } \\
\hline $\mathrm{K}$ & 1,02 & 0,10 & 0,27 & 0,66 & 0,12 & 0,03 & 305 & 13 & 48 & 43 & 43 & 2,9 \\
\hline $\mathrm{N}$ & 0,89 & 0,08 & 0,30 & 0,62 & 0,11 & 0,03 & 328 & 11 & 45 & 37 & 33 & 2,2 \\
\hline S11 & 0,95 & 0,09 & 0,31 & 0,62 & 0,12 & 0,04 & 319 & 16 & 53 & 49 & 53 & 6,3 \\
\hline S75 & 1,06 & 0,11 & 0,27 & 0,67 & 0,13 & 0,04 & 297 & 15 & 48 & 42 & 43 & 2,4 \\
\hline \multicolumn{13}{|l|}{ Kök } \\
\hline K & 0,72 & 0,07 & $0,20 \mathrm{ab}$ & 0,92 & 0,11 & 0,04 & 712 & 19 & $66 \mathrm{~b}$ & $54 \mathrm{~b}$ & $39 a b$ & 5,8 \\
\hline $\mathrm{N}$ & 0,62 & 0,04 & $0,19 \mathrm{a}$ & 0,85 & 0,10 & 0,03 & 668 & 13 & $72 b$ & $58 \mathrm{~b}$ & $29 a$ & 4,7 \\
\hline S11 & 0,62 & 0,05 & $0,24 b c$ & 0,79 & 0,11 & 0,04 & 688 & 18 & $67 b$ & $79 a$ & $49 b$ & 6,1 \\
\hline S75 & 0,74 & 0,06 & $0,22 b$ & 0,88 & 0,11 & 0,04 & 536 & 15 & $56 a$ & $60 \mathrm{~b}$ & $37 \mathrm{a}$ & 5,1 \\
\hline
\end{tabular}

Çizelge 8. Fidanların (ibre, gövde, kök dahil tüm kısımları) birim alanda topraktan aldıkları besin maddesi miktarları (mg $\mathrm{m}^{-2}$ )

\begin{tabular}{lcccccccccccc}
\hline İşlem & $\mathrm{N}$ & $\mathrm{P}$ & $\mathrm{K}$ & $\mathrm{Ca}$ & $\mathrm{Mg}$ & $\mathrm{S}$ & $\mathrm{Fe}$ & $\mathrm{Cu}$ & $\mathrm{Mn}$ & $\mathrm{Zn}$ & $\mathrm{B}$ & $\mathrm{Mo}$ \\
\hline $\mathrm{K}$ & 2776 & 236 & 645 & 2342 & 333 & 214 & 184 & 5,2 & 22 & 18 & 16 & 1,9 \\
$\mathrm{~N}$ & 4438 & 336 & 1343 & 3859 & 570 & 381 & 283 & 5,7 & 35 & 25 & 20 & 1,8 \\
$\mathrm{~S} 11$ & 3113 & 251 & 958 & 2440 & 382 & 358 & 196 & 6,2 & 27 & 27 & 22 & 2,5 \\
S75 & 2840 & 241 & 689 & 2408 & 342 & 304 & 138 & 4,3 & 20 & 18 & 14 & 1,3 \\
\hline
\end{tabular}

\section{Tartışma ve sonuç}

Fidanlık faaliyetleri sonucunda üretilecek olan fidanların kalitesi bir yandan fidanlığın toprak ve iklim özelliklerinden, bir yandan da fidanlara uygulanan kültürel yöntemlerden etkilenmektedir. Sağlıklı ve kaliteli fidan üretimi için toprağın kaba bünyeli ve geçirgen olması, toprak pH'sının ise hafif asit (6-7) olması önerilmektedir (Gülçur 1959, 1962a,b; van den Driessche, 1984; Örtel, 1994). Eğirdir Orman Fidanlığı dahil Ülkemizin pek çok fidanlığında ise hem topraklar ağır bünyeli hem de reaksiyon alkali seviyelerdedir. Ağır bünye, zayıf drenaj ve aşırı sulama gibi nedenlerden dolayı ortaya çıkan havalanma problemi yüksek $\mathrm{pH}$ ile bir araya geldiğinde özellikle mikro besinlerin alınabilirliğini olumsuz etkilemektedir. Çalışmamıza konu olan Toros sediri her ne kadar doğal ortamlarında nötr-hafif alkali topraklara uyum sağlamış olsa da, havalanmaya bağlı sorunlara karşı son derece hassastır.

Çalışmamızın yapıldığ 1 fidanlıkta toprak pH'sının 8 civarında olması, toprağın nispeten ağır bünyeli olması, dolaysiyla infiltrasyon, drenaj ve havalanma problemlerinin olması fidanlarda beslenme ve gelişim problemlerinin olabileceğini işaret etmektedir. Zira, deneme yapılan fidanlık yastıklarında geçmiş yıllarda da kısa boylu, cılız, ibreleri sarımsı-yeşil renkli fidanların oranının oldukça fazla olduğu gözlenmiştir. Çalışmamızda kullanılan amonyum sülfat ve kükürt gübrelerinin her ikisi de asit yapılı gübrelerdir ve toprak pH'sını düşürmesi beklenir. Araştırma sonuçlarımızı göre, her iki gübre de $\mathrm{pH}$ 'da kısmen düşüş sağlamış, ancak bu düşüş beklenen miktarda ve kalıcı olmamıştır. Düşünün beklenenden az olmasının muhtemel nedeni toprağın ağır bünyesine ve yüksek kireç içeriğine bağlı olarak tamponlama kapasitesinin yüksek olmasından kaynaklanmış olabilir. Dahası, fidanlığa uygulanan sulama suyunun da yüksek pH'lı ve kireçli olması da bu duruma katkı sunmaktadır.
Gübreleme işlemlerinin fidan gelişimine etkileri azotlu gübre için pozitif ve oldukça belirgin iken, kükürtte önemsiz ve kısmen negatif olmuştur. Özellikle fidan boyu, kök yüzey alanı ve fidan kuru ağırlıkları azot uygulamasından sonra önemli oranda artmıştır. Azotun bitki gelişimine pozitif etkileri zaten bilinen bir durumdur (Marschner 1995), ancak bu etkinin boyutu fidanlık şartlarına ve fidan türüne göre değişmektedir. Bizim fidanlık toprağımızdaki organik madde ve dolayısıyla toplam azot miktarının nispeten düşük-orta seviyede olması bu konuda bir ihtiyaç olabileceğini düşündürmektedir.

Dahası, her y1l fidan sökümüyle birlikte önemli miktarda organik madde ve mineral besinler sahadan uzaklaştırılmaktadır. Ülkemiz fidanlıklarında yapılan bir çalışmada kızılçam, karaçam, sarıçam ve sedir gibi ibreli türlerin bir hektarlık alandan $10-161 \mathrm{~kg} \mathrm{~N}, 3-14 \mathrm{~kg}$ P ve $12-$ $59 \mathrm{~kg} \mathrm{~K}$ uzaklaştırdığ1 ortaya konmuştur (Tacenur, 1985). $\mathrm{Bu}$ çalışmada ise 1 yaşlı sedir fidanlarının topraktan $\mathrm{m}^{2} \mathrm{de}$ 2.8-4.4 g N aldığı tespit edilmiştir. Bu rakamların hektardaki karşılığı 28-44 kg'dır. Hızlı büyüyen türlerde ve çok yıllık fidanlarda bu rakamlar çok daha yüksek olacaktır. Topraktan kaybolan bu besinlerin yerine organik veya inorganik kökenli besinlerle takviye yapılması üretimde ve kalitede devamlılık açısından son derece önemlidir. Bizim fidanlıklarımızda, genelde tohum kapatma materyali olarak kullanılan ibre, kozalak ve kabuk karışımı sahadan çıkarılan organik maddenin ve besinlerin yerini almaktadır. Bu karışım fiziksel özellikleri bakımından iyi olsa da, kimyasal içerik bakımından pek de zengin olmayan, yavaş ayrıșan ve fidan beslemesine katkısı sınırlı olan düşük kaliteli maddelerdir (Gürlevik vd., 2003). İnorganik gübreler ise genelde fidanların aşırı gelişimine neden olacağı endişesiyle en düşük seviyelerden uygulanmaktadır. Oysaki İspanya gibi Akdeniz ülkelerinde yapılan güncel bazı çalışmalarda, fidanlık şartlarında iyi beslenmiş fidanların kurak ağaçlandırma sahalarında hem tutma başarısını hem de fidan gelişimini artıracağını göstermektedir (Puértolas vd., 2003; 
Oliet vd., 2005, 2009; Luis vd., 2009). Ülkemizde de dengeli ve iyi beslenmiş fidanların üretimine dönük çalışmalarla bu konunun aydınlatılması büyük önem arz etmektedir.

$\mathrm{Bu}$ çalışmada kullanılan azot dozu fidanlarda boy gelişimini ciddi oranda artırmakla birlikte, gövde /kök oranı hala 1,7'nin altında kalmıştır ve fidanlarda aşırı gelişim söz konusu değildir. Gövde/kök oranında aşırı artış (3/1 ve üzeri) genellikle dengesiz gelişen bir fidanı anlatmaktadır. Böyle hızlı tepe gelişimi yapan fidanlar bol yağışlı yetişme ortamlarında iyi performans gösterirken, marjinal, yarı kurak sahalarda bu oranın yüksek olması fazla istenmeyen bir özelliktir. Bu tür fidanların transpirasyon yüzeylerinin fidanı besleyen köke oranının aşırı fazla olması dikim sonrasında su stresinin yaşanmasına ve yaşama yüzdesinin düşmesine sebep olmaktadır (Dirik, 1990). Ancak çalışmamızda görülen artışa rağmen elde edilen fidanların gövde/kök oranı hala kabul edilebilir sınırların altındadır.

Kükürtlü gübrelemenin fidan ibrelerindeki $S$ konsantrayonunu belirgin şekilde artırmasına rağmen, azotlu gübrelemenin etkisi sınırlı kamış hatta ilginç bir şekilde negatif yönde olmuştur. Azot konsantrasyonundaki bu düşük literatürde seyreltme (dilution) etkisi denen, fidan dokularındaki hızlı büyümeyle birlikte doku içerisindeki besin konsantrasyonunun düşmesi ile açıklanabilir (Marschner, 1995). Zira, toprağa verilen küçük miktarda azota fidanlar hızla tepki vermiş ve neticede hızlı gelişen fidanlarda N konsantrasyonu düşmüştür.

Gübrelemenin çap gelişimine olumlu bir etkisi ise görülmemiştir. Zira, çap daha ziyade siklık tarafından kontrol edilen bir özelliktir (Bowles, 1981; Duryea, 1984; Albayrak Çatal, 2002; Yıldız, 2005). Çalışmamızda fidanlık yastığındaki mevcut fidan sayıları oldukça yüksektir ve 510 ile 627 arasında değişmiştir. En sık işlem olan S11 işlemi aynı zamanda çapı en düşük olan işlem olarak belirlenmiştir. Aynı fidanlıkta boylu ardıçta (Juniperus excelsa) yapılan bir diğer çalışma da azot işleminin çapa önemli bir etkisinin olmadığı gösterilmiş, ancak sıklığın son derece önemli olduğu belirtilmiştir (Eser 2007).

Çalışmada yetiştirilen fidanların TSE standartlarına göre dağılımı oldukça ilginç sonuçlar vermiştir. Başta da bahsedildiği gibi, çalışma sahasında toprak pH'sındaki ve havalanmasındaki problemlerden ve ayrıca aşırı sıklıktan dolayı fidanlarda gelişme bozuklukları görülmekte idi. Mevcut düzende yetiștirilen kontrol fidanlarının yalnızca \% 7 si morfolojik olarak kullanılabilir fidan ebatlarında (çap $>$ $2 \mathrm{~mm}$ ve boy $>6 \mathrm{~cm}$ ) iken, bu oran azot uygulaması ile \% 57'ye çıkmıştır. Metrekaredeki kullanılan fidan sayıları ise kontrolde yalnızca 34 adetten azot işleminde $315^{\prime} \mathrm{e}$ çıkmıştır. Kükürt işlemleri ise kayda değer bir artış sunmamıştır. Neticede, birim alanda elde edilen morfolojik olarak kaliteli fidan miktarının artırılmasında azotlu gübreleme önemli bir yöntem olarak önümüze çıkmaktadır.

Orman fidanlıklarındaki kalite sorunu sadece toprakla ilgili olmayıp, uygulayıcıların kendi tercihleri ile de ilgili olabilmektedir. Örneğin, uygulayıcılar fidanlıkta iş akışı içerisindeki belirsizliklerden (ekilecek tohumun kalitesi, sezon içerisinde yaşanacak iklim koşulları, hastalıklar vb.) dolayı tedbiren gereğinden daha sı ekim yapabilmektedirler. Her şey yolunda giderse, bu kez de gereğinde çok daha sık fidan elde edilmektedir. Bunların seyreltilmesi ve bakımı ise ayrı bir sorun teşkil etmektedir ve çoğu zaman işgücü ve zaman kısıtlarından dolayı ihmal edilmektedir. Neticede, birim alandan çok fazla fakat düşük kalitede fidan üretimi ile karşı karşıya kalınmaktadır. Bu durumda bir yandan çok fazla iskarta fidan imha edilmek durumunda kalınmakta, diğer yandan da kaliteli fidanların üretim maliyeti artmaktadır (Alkan, 2002).

Sonuç olarak, Eğirdir Orman Fidanlığında $1+0$ yaşlı çıplak köklü Toros sediri fidanlarına metrekareye $10 \mathrm{~g}$ azot (yaklaşık $50 \mathrm{~g}$ amonyum sülfat) gübrelemesi yapılmasının uygun olabileceği görülmüştür. Alkali toprak sorununu gidermede kullanılacak S uygulamasının ise vejetasyon mevsimi öncesinde toprak hazırlığı sırasında yapılması ve mümkünse bu çalışılmadakinden biraz daha yüksek dozlarda yapılması uygun olabilir. Ancak bu işlemler yapılırken pek çok gübrenin (amonyum ve kükürt dahil) küçük fidanlar için zehir etkisi yapabileceği unutulmamalı, vejetasyon mevsimi içerisinde verilecek gübreler mümkünde küçük dozlar halinde birkaç seferde verilmelidir.

\section{Teșekkür}

$\mathrm{Bu}$ çalışma Süleyman Demirel Üniversitesi Fen Bilimleri Enstitüsü Orman Mühendisliği Anabilim Dalı'nda Yüksek Lisans Tezi olarak hazırlanmıştır. Çalışmaya finansal destek sunan SDÜ BAP Yönetim Birimi'ne katkılarından dolayı teşekkür ederiz. Ayrıca, çalışmanın arazi aşamasında yardımlarını esirgemeyen Mert MERCAN, Mustafa YEĞEN ve Durmuş ÇETINNKAYA ve Çağlar BAŞSÜLLÜ'ye, çalışmada kullanılan dijital fotoğraflama tekniği yardımı ile kök yüzey alanının ölçümünde ve diğer birçok konuda yardımını esirgemeyen Ogün Çağlayan TÜRKAY'a teşekkür ederiz. Çalışmanın gerçekleştirildiği Eğirdir Orman Fidanlığı personeline ayrıca teşekkürü borç biliriz.

\section{Kaynaklar}

Albayrak Çatal, Y., 2002. Toros sediri (Cedrus libani A.Rich.)'nde yetiştirme sıklığının bazı morfolojik fidan özelliklerine etkisi. Yüksek Lisans Tezi, SDÜ, Fen Bilimleri Enstitüsü, Isparta.

Alkan H., 2002. Kalitesizliğin önemli bir boyutu: Maliyet artışı (Orman ağacı fidanı üretimine ilişkin bir değerlendirme). SDÜ Orman Fakültesi Dergisi, 2: 97118.

Anonim, 1999. Eğirdir Orman Fidanlığı 1999-2003 Yılı Rotasyon Plan1, Isparta.

Atalay, İ., 1987. Sedir (Cedrus libani A. Rich.) Ormanlarının Yayılış Gösterdiği Alanlar ve Yakın Çevresinin Genel Ekolojik Özellikleri ile Sedir Tohum Transfer Rejyonlaması. Orman Genel Müdürlüğü Yayın No: 663, s.167, Ankara.

Bowles, G.P., 1981. Nursery spacing and seedling quality. In Chavosse, C.G.R. (Ed.), Forest Nursery and Establishment Practice in New Zealand, New Zealand Forest Service FRI Symposium No 22: 101-112.

Boydak M., 2014. Toros sedirinin ekolojisi, doğal gençleştirilmesi ve bu türle karstik alan ağaçlandırmaları. I. Ulusal Akdeniz Orman ve Çevre Sempozyumu, "Akdeniz Ormanlarının Geleceği: Sürdürülebilir Toplum ve Çevre”, 22 - 24 Ekim 2014 Isparta, s. 1-25. 
Boydak, M., Çalıkoğlu, M., 2008. Toros Sedirinin (Cedrus libani A. Rich.) Biyolojisi ve Silvikültürü. OGEM-VAK Yainları, s. 284, Ankara.

Brohi A.R., Doran İ, Gürlevik N. 2012. Ormanc1lık ve peyzaj ağaçlarında bitki besleme yönetimi. In M.R. Karaman (Ed.), Bitki Besleme - Sağlıklı Bitki, Sağlıklı Üretim, Gübretaş Rehber Kitaplar Dizisi: 2, Duman Ofset Matbaacılık, Ankara.

Demiralay, İ., 1993. Toprak Fiziksel Analizleri. A.Ü. Ziraat Fak. Yayınları No:143, Erzurum.

Dickson, A.A.L., Leaf, J., F., Hosner, 1960. Quality appraisal of white spruce and white pine seedlings stock in nurseries. Forestry Chronicle 36:10-13.

Dirik, H., 1990. Dikim şoku. İÜ Orman Fakültesi Dergisi, B40(3): 105-116.

Duryea, M.L., 1984. Nursery cultural practices: Impacts on seedling quality. In Duryea, M.L., Landis, T.D. (Eds), Forest Nursery Manual: Production of Bareroot Seedlings, Chapter 15, Forest Research Laboratory, Oregon State University, pp.143-164.

Eser, Y., 2007. Boylu ardıç (Juniperus excelsa Bieb)'ın fidanlık tekniği açısından önemli görülen yetiştirme sıklığı ve gübrelemenin fidan morfolojik özellikleri üzerine etkileri. Yüksek Lisans Tezi, SDÜ, Fen Bilimleri Enstitüsü, Isparta.

Gülçur, F., 1959. Daimi bir orman fidanllğı için yer seçiminde göz önünde tutulacak esaslar. İ̈̈ Orman Fakültesi Dergisi Seri B, 12(1): 47-54.

Gülçur, F., 1962a. Orman fidanlığı topraklarının verimlilik standartları ve verimliliğe tesir eden çeşitli faktörlerin 1slahı. İÜ Orman Fakültesi Dergisi, Seri B, 12: 67-73.

Gülçur, F., 1962b. Orman fidanlıklarında kullanılan gübre çeşitleri ve gübrelemede göz önünde tutulacak esaslar. İÜ Orman Fakültesi Dergisi, Seri B, 12: 41-52.

Gürlevik, N., Kelting, D.L., Allen, H. L., 2003. The effects of vegetation control and fertilization on net nutrient release from decomposing loblolly pine needles. Can. J. For. Res. 33: 2491-2502.

Gürlevik, N., Gültekin, H.C., 2009. Bitki Besleme. T.C. Çevre ve Orman Bakanlığı Ağaçlandırma ve Erozyon Kontrolü Genel Müdürlüğü. Tohum, Fidan Üretimi, Ağaç Islahı ve Mekanizasyon Semineri, Eskişehir, 148158.

Havlin, J.L., Beaton, J.D, Tisdale, S.L, Nelson, W.L, 1999. Soil Fertility and Fertilizers: An Introduction to Nutrient Management. Sixth edition. Pearson Prentice Hall, NJ.

Hizalan, E., Ünal, H., 1965. Topraklarda Önemli Kimyasal Analizler. A.Ü. Zir. Fak. Yay. No:278, Yrd. Ders Kitab1 No:97, A.Ü. Basımevi Ankara.

Hocaoğlu, Ö.L., 1966. Toprakta Organik Madde, Nitrojen ve Nitrat tayini. Atatürk Üniversitesi, Ziraat Fakültesi, Zirai Araştırma Enstitüsü, Teknik Bülten, No: 9.

Kacar, B., 1995. Bitki ve Toprağın Kimyasal Analizleri III. Ankara Üniversitesi, Ziraat Fakültesi, Eğitim Araştırma ve Geliştirme Vakfı Yayınları, No: 3, Ankara.

Kantarcı, M.D., 1990. Türkiye'de sedir ormanlarının yayılıș alanında ekolojik ilişkiler. Uluslararası Sedir Sempozyumu, Ormancılık Araştırma Enstitüsü Muhtelif Yayınlar No: 59, s.12-25, Ankara.

Karaöz, M.Ö., 1992. Gübreler ve peyzaj uygulamalarında gübreleme teknikleri. İÜ Orman Fakültesi Dergisi, Seri B, 42(3-4): 49-60.
Katkat, V., Kacar, B., 2011. Gübreler ve Gübreleme Tekniği. 4. Baskı, Nobel Yayın Dağıtım.

Lindsay, W.L., Norvell, W.A., 1978. Development of a DTPA soil test for zinc, iron, manganese, and copper. Soil Science Society of America Journal, 42: 421-428

Luis, V.C., Puértolas, J., Climent, J., Peters, J., GonzálezRodríguez A.M., Morales, D., Soledad Jiménez, M., 2009. Nursery fertilization enhances survival and physiological status in Canary Island pine (Pinus canariensis) seedlings planted in a semiarid environment. European J Forest Research, 128: 221-229.

Marschner, H., 1995. Mineral Nutrition of Higher Plants. Academic Press, 889 p, London.

Mayer, H., Sevim, M., 1959. (Çeviri: Necmettin Çepel), Lübnan Sediri - Lübnan'daki 5000 yıllık tahribatı, Anadolu'daki bugünkü yayılış sahası ve bu ağaç türünün Alplere tekrar getirilmesi hakkında düşünceler. İ̈̈ Orman Fakültesi Dergisi Seri B, 9(2): 111-142.

OATIAM, 2009. Tohum Meşçereleri. OGM Orman Ağaçları ve Tohumları Islah Araştırma Enstitüsü Müdürlüğü, http://ortohum.ogm.gov.tr/Sayfalar/TohumMescereleri.aspx; Erişim tarihi: 15.10.2016.

OGM, 2005. Sedir Ormanlarının Rehabilitasyonu Eylem Planı. T.C. Çevre ve Orman Bakanlığı, Orman Genel Müdürlüğü, 24s, Ankara.

OGM, 2008. Orman Atlası. T.C. Çevre ve Orman Bakanlığ 1 , Orman Genel Müdürlüğü, 88s, Ankara.

OGM, 2015. Orman Ağacı Fidan Üretimi 2009-2015, Ormancılık İstatistikleri 2015. Orman Genel Müdürlüğü İstatistikleri, Ankara. https://www.ogm.gov.tr/ekutuphane/Istatistikler/Forms/ AllItems.aspx

Oliet, J., A., Planelles, R., Artero, F., Jacobs, D.F., 2005. Nursery fertilization and tree shelters affect long-term field response of Acacia salicina Lindl. planted in Mediterranean semiarid conditions. Forest Ecology and Management, 215: 339-351.

Oliet, J.A., Planelles, R., Artero, F., Valverde, R., Jacobs, D.F., Segura, M.L., 2009. Field performance of Pinus halepensis planted in Mediterranean arid conditions: relative influence of seedling morphology and mineral nutrition. New Forests, 37: 313-331.

Örtel, E., 1994. Sedir fidanlık tekniği. In Eler, Ü. (Ed.), Sedir, Ormancılık Araştırma Enstitüsü Muhtelif Yayınlar No: 66, El Kitabı Dizisi: 6, Ankara, s. 195-210.

Özçelik R., Özkan K., 1997. Fidan yetiştirmeye uygunluk durumu açısından Eğirdir Orman Fidanlığ 1 toprak özelliklerinin zamana bağlı değişimi. Batı Akdeniz Ormancılık Araştırma Enstitüsü Yayınları, Dergi Serisi, 3: 99-113.

Peech, M., 1965. Hydrogen-Ion Activity. In Black, C.A., (Ed.), Methods of Soil Analysis, Part 2, American Society of Agronomy, Madison, Wisconsin, USA, pp. 914-926.

Puértolas, J., Gil, L., Pardos, J.A., 2003. Effects of nutritional status and seedling size on field performance of Pinus halepensis planted on former arable land in the Mediterranean basin. Forestry, 76(2): 159-168.

Ryan, J., Estafan, G., Rashid, A., 2001. Soil and plant analysis laboratory manual. 2nd ed., ICARDA and NARS, Aleppo, Syria, pp. 135-140. 
Sevim, M., 1955. Lübnan Sedirinin Türkiye'deki Tabii Yayılışı ve Ekolojik Şartları. T.C. Ziraat Vekaleti, Orman Umum Müdürlüğü Yayınlarından, Neşriyat Sıra No: 149, Seri No:24, 99 s, Yenilik Yayınevi, İstanbul.

Tacenur, İ.A., 1985. Bazı yerli ağaç türlerimizin fidanlarının yapraklarındaki besin konsantrasyonları ve topraktan aldıkları besin miktarları. Orman Mühendisliği Dergisi, 12: 27-35.

TS2265, 1988. İğne yapraklı ağaç fidanları. Türk Standartları Enstitüsü, Ankara.

U.S. Salinity Laboratory Staff, 1954. Diagnosis and Improvement of Saline and Alkalin Soils. Agricultural Handbook No. 60, USA. van den Driessche, R., 1984. Soil fertility in forest nurseries. In Duryea, M.L., Landis T.D. (Eds.), Forest Nursery Manual: Production of Bareroot Seedlings. Forest Research Laboratory, Oregon State University. Corvallis. 386 p.

Yıldız, D., 2005. Bazı yetiştirme tekniklerinin Toros sediri (Cedrus libani A. Rich.)'nde fidan morfolojisine etkisi. Yüksek Lisans Tezi, SDÜ Fen Bilimleri Enstitüsü, Isparta. 